\title{
Nuevos hallazgos literarios: dos volúmenes manuscritos de Trigueros
}

Francisco Aguilar Piñal

CES.XVIII, núm. 17 (2007), págs. 5-39. 
RESUMEN: En esta investigación se da cuenta del hallazgo de un manuscrito autógrafo de Cándido María Trigueros, localizado en la Biblioteca Universitaria de Sevilla, en que se encuentran algunas cartas, su traducción de la Eneida, una Adición al discurso sobre el número y celibato del clero, una disertación sobre el teatro, y cuatro poemas: Los cuadros de Murillo, El templo de la felicidad, La Paz en la Guerra, hasta hoy desconocido, y Las naves de Cortés. Poema épico en un Canto, cuyo texto se edita cotejado con el original depositado en la RAE.

Palabras clave: Cándido María Trigueros. Poesía. Certamen. Real Academia Española. Hernán Cortés. 
El fondo antiguo de la Biblioteca Universitaria de Sevilla es una caja de sorpresas. Allí encontré el manuscrito de la perdida tragedia de Cadalso Solaya o los circasianos, ya editada ${ }^{1}$, de la que di noticia en el Boletín del antiguo Centro de Estudios del Siglo XVIII ${ }^{2}$. Y hace pocos meses, favorecido de nuevo por la diosa Fortuna, tuve entre mis manos un interesantísimo manuscrito, esta vez autógrafo en su casi totalidad, con algunos poemas y otros textos desconocidos del académico sevillano y madrileño Cándido María Trigueros, cuya biografía tracé hace ya veinte años ${ }^{3}$. Como etapa previa a esta monografía, había buscado manuscritos de Trigueros en Madrid, Sevilla, Barcelona, Valencia, Toledo, Santander ${ }^{4}$ y otros varios depósitos, públicos y privados, de documentación y bibliografía, que dieron lugar a un avance bibliográfico del escritor toledano, que ahora habrá que aumentar.

El manuscrito en cuestión es un volumen facticio, cosidas todas sus páginas, pero sin contenido uniforme, misceláneo de prosa y verso, con textos ya conocidos y publicados junto a otros desconocidos, unos firmados y otros no. La numeración de los folios es moderna, a lápiz, incluidos varios folios en blanco. La densidad de la tinta varía de unas páginas a otras, aunque casi todo es fácilmente legible. Aunque los textos no están fechados, fueron escritos por el autor, sin duda en Carmona, entre 1776 y 1783, antes de su marcha a Madrid en 1785 para ocupar el cargo de archivero en el Ministerio de Hacienda. Voy a resumir el contenido, con algún comentario a vuelapluma ${ }^{6}$.

1 José Cadalso, Solaya o los circasianos. Tragedia inédita. Edición, introducción y notas de Francisco Aguilar Piñal. Madrid, Ed. Castalia, 1982 (Clásicos Castalia, 118). Hay otra edición, hecha por la misma editorial, sin mi consentimiento, unida a la autobiografía de Cadalso, preparada por J. Camarero (Clásicos Castalia, 73).

2 Francisco Aguilar Piñal, «Un hallazgo literario», en Boletín del Centro de Estudios del siglo XVIII, Universidad de Oviedo, 7-8 (1980), págs. 179-180.

3 Francisco Aguilar Piñal, Un escritor ilustrado: Cándido María Trigueros. Madrid, Consejo Superior de Investigaciones Científicas, 1987.

4 Francisco Aguilar Piñal, «Manuscritos de Trigueros conservados en la Biblioteca de Menéndez Pelayo», Boletín de la Biblioteca de Menéndez Pelayo, 4 (1963), págs. 367-380.

5 Francisco Aguilar Piñal, «La obra "ilustrada” de don Cándido María Trigueros. Avance bibliográfico», en Revista de Literatura, XXIV, 67-68 (1968), págs. 31-56.

6 Obras de Dn. Cándido María Trigueros. Autógrafo de 260 folios en cuarto. Biblioteca Universitaria de Sevilla, ms. A-333/233. 
El volumen comienza con una breve nota biográfica, de puño y letra de Trigueros, quizás para satisfacer los deseos de su editor, Juan Nepomuceno González de León, o de algún amigo, ávido de noticias literarias, como el franciscano fray Rafael Rodríguez Mohedano ${ }^{7}$. Esta breve reseña biográfica no añade gran cosa a lo ya conocido. Comienza, en tercera persona, haciendo pública su timidez (quizá falsa modestia) con estas palabras:«Dn. Cándido María Trigueros, aunque por afición y gusto ha escrito muchas cosas, no ha publicado jamás ninguna. Algunos le han impreso varias, ya sin su nombre, ya con él; ya poéticas, ya en prosa». Da noticia después de las varias disertaciones publicadas por la Real Academia Sevillana de Buenas Letras, y de las poesías filosóficas que «le han impreso», detallándolas por sus títulos, hasta la última sobre «La mujer», obra que se interrumpió, según dice, aunque tenía otros poemas preparados, «por haber muerto el editor» (es decir, Juan Nepomuceno González de León, abogado sevillano, amigo, editor y corresponsal).

Continúa la relación con el poema de San Felipe Neri al clero (1775), las Obras de Melchor Díaz de Toledo (1776), de la cual dice que «las escrivió imitando los buenos Poetas de aquel siglo, para tentar el gusto y tino de algunos a quien hizo creer ser antiguos», y El viage al cielo del Poeta filósofo (1777). Cita sus tragedias (Ciane, Viting, Los Theseides, Egilona, Fedra «y otras»), sus comedias (Cándida, Las dos ynglesas —desconocida— El hipócrita, Los Duendes, Los salteadores, Don Amador «y otras»). Además, «varios dramas menores, ya para música, ya sin ella», y «varios poemillas», como El pláceme de las majas (1765). En total, «muchísimas poesías de todos géneros, que pudieran llenar 10 volúmenes, o 12. En prosa, muchas disertaciones sobre muy varios asuntos de antigüedades, historia, política, etc., y muchos volúmenes de apuntaciones varias». Menciona La observadora y varias traducciones de griego, latín, italiano, inglés y francés, el Plan de estudios ${ }^{8}$ y dos discursos sobre la «industria lanar»y la «industria labrantil» ${ }^{9}$, concluyendo que ha escrito «muchas cosas que paran en poder de los aficionados». Es posible que este autógrafo sevillano pueda ser incluido entre estas últimas ${ }^{10}$.

7 Francisco Agullar Piñal, «Fray Rafael Rodríguez Mohedano (1722-1787) y Cándido María Trigueros (1736-1798)», Chrónica Nova, 24 (1997), págs. 317-335. Rep. en El académico Cándido María Trigueros, Madrid, Academia de la Historia, 2001, págs. 217-230.

8 Cándido María Trigueros, Plan de estudios (1768). Estudio preliminar por Francisco Aguilar Piñal. Barcelona, Universidad, 1984. Rep. en El académico Cándido María Trigueros. Madrid, Academia de la Historia, 2001, págs. 185-216.

9 Publicados en el Semanario de Agricultura y Artes, XVI (1804), págs. 56-64 y 72-78. Con anterioridad, Jovellanos había iniciado las gestiones para su publicación, con la aprobación de Floridablanca, sin éxito. (Vid. mi estudio La obra botánica de Trigueros en Carmona, carta 49, del 20 de mayo de 1784).

10 De origen no precisado, fue adquirido por la Biblioteca Universitaria de Sevilla a un conocido anticuario de la ciudad. 
Comienzan los textos con Los quadros de Murillo. Cuento en rima libre, poema que presenta numerosas variantes con respecto al leído en la Real Academia de Bellas Artes de Sevilla y publicado en la Distribución de premios a los discípulos de las Bellas Artes (1783), folleto conservado en ejemplar único en la Institución Colombina de Sevilla (63-3-20) y después editado por mí en el Archivo español de Arte como el primer elogio poético dedicado a Murillo ${ }^{11}$. El poema, al que subtitula aquí como «Cuento en rima libre», está escrito en limpio y se aclara, al margen, que el «docto Magistrado» al que se dedica es don Francisco de Bruna y Ahumada, oidor y regente de los Reales Alcázares, en cuya sede se distribuyen los premios.

Sigue el poema titulado El templo de la felicidad, original corregido, anterior a la copia conservada en la Biblioteca Nacional de Madrid (ms. 17676) que perteneció a Gayangos. En la portada, después del título y del autor, se indica que fue escrito «para leer en la Junta pública de la Real Sociedad Patriótica de los Amigos del País de Sevilla en 23 de Noviembre de 1783» y sigue la cita latina «Numquam libertas gratior extat quam sub Rege PIO»(Claudian.laud Stilicon). Es sabido que Trigueros fue nombrado socio correspondiente de la Económica (antes Patriótica) de Sevilla en 22 de enero de 1778, a petición de Jovellanos ${ }^{12}$, y que contribuyó con sus escritos a la buena marcha de la Sociedad, leyendo sus poemas en los repartos de premios desde 1778, y publicando en el primer tomo de Memorias (1779) su oda Los Amigos del País Bético, en la que se proclama abanderado de la utilidad («Yo de la utilidad cantaré sólo...»). Su gran héroe es el rey Carlos III, a quien dedica El templo de la felicidad, ya publicado ${ }^{13}$.

Para la misma Sociedad había escrito dos años antes otro poema, La Paz en la Guerra, hasta hoy desconocido, de 196 endecasílabos asonantados ${ }^{14}$. Sempere asegura que el autor fue premiado en esta ocasión con una medalla de plata ${ }^{15}, \mathrm{y}$ en este autógrafo, que Trigueros subtitula «Sueño», se especifica que fue «leído en la Junta Pública de la Real Sociedad Patriótica de los Amigos del País de Sevilla en 23 de noviembre de 1781». El autor, como era su costumbre, finge una visión onírica en la que se le aparece la Paz, y a la que suplica: «Vuelve, Paz, vuelve a dar días serenos / y haz que se perfeccione el beneficio / que al Padre Betis, y su fértil Clima, / procuran y desean sus Amigos».

11 Francisco Aguilar Piñal, «Un poema del siglo XVIII en elogio de Murillo», Archivo español de Arte, 233 (1986), págs. 84-90. Rep. en Temas sevillanos (Segunda serie), Sevilla, Universidad, 1988, págs. 31-48.

12 José Miguel Caso González, Obras completas de Jovellanos. Correspondencia (1767-1794). Tomo II, Oviedo, Cátedra Feijoo, 1985, pág. 107.

13 El poema, con extenso comentario, lo publiqué en el Homenaje a la profesora María Dolores Tortosa Linde. Granada, Universidad, 2003, págs. 13-26.

14 Vid. Un escritor ilustrado..., pág. 156, núm. 70.

15 J. Sempere y Guarinos, Ensayo..., VI, pág. 102. 
Otra institución, la Real Academia Española, es la destinataria del siguiente poema en ochenta octavas, Las naves de Cortés. Poema épico en un Canto, «que no ganó el premio propuesto por la Real Academia Española en la Gaceta de Madrid del martes 7 de octubre de 1777». Concurrieron a este certamen, como digo en otro lugar ${ }^{16}$, un total de cuarenta y tres poetas, entre los que estaban Nicolás Fernández de Moratín, José Iglesias de la Casa y José María Vaca de Guzmán, que resultó premiado, a la sazón rector del Colegio de Santiago de los Caballeros Manriques, en Alcalá de Henares ${ }^{17}$. La Academia seleccionó catorce poemas y quemó los pliegos correspondientes a los no premiados. La mayoría de estos textos se conservan en el archivo de la Academia, marcados los seleccionados con una letra cada uno, de la $\mathrm{A}$ a la $\mathrm{N}$, que sirvieron para las votaciones. El poema marcado con la M, aprobado en primera revisión por los académicos Vicente García de la Huerta, José Vela, Benito Bails, Enrique Ramos y Manuel Uriarte, lo reconocí en cuanto lo tuve en mis manos, por ser de letra inconfundible de Trigueros, y así lo dejé escrito y comenté en mi biografía del «poeta filósofo».

En el prólogo, Trigueros escribe que

el autor de este poema ha tenido presente el juicioso precepto de Aristóteles al disponer la fábula que le parecía convenía al asunto propuesto por la Academia, pero no ha querido valerse de hechos inventados... ha procurado pintar, aun al referir, y en lo que refiere solamente ha querido escoger lo que juzgaba que convenía a la pintura.

El poeta plantea la argumentación del canto como una empresa de religión, similar a la expulsión de los árabes de la península, con la intervención de Dios, que envía a Cortés, como deidad personificada, a la Confianza, para que disipe las dudas del caudillo extremeño. Resulta curioso, y quizás significativo de algunos intelectuales de la época, la mezcla del Dios cristiano con las deidades paganas, incluso con otras inventadas por él, en este caso la Confianza. Trigueros, que era subdiácono de la Iglesia católica, y ferviente defensor de la cristiandad tanto como de la monarquía, se atreve ingenuamente a presentar las figuras antropomórficas de los dioses, sean paganos o no, como una «comunidad» divina, a las órdenes del Ser Supremo, dios de los cristianos, para influir en la

16 Francisco Agullar Piñal, Un escritor ilustrado..., pág. 152. Mauricio FabBri, «Las naves de Cortés destruidas en la épica española del siglo XVIII», Revista de Literatura, XLII (1980), págs. 53-74. Traducido al italiano, «Le navi incendiate di Cortés come tema e problema letterario e politico», en Vagabondi, visionari, eroi. Padua, 1984. Fabbri desconocía entonces la participación de Trigueros.

17 Ángel González Palencia, «Don José María Vaca de Guzmán, el primer poeta premiado por la Academia Española», Boletín de la Real Academia Española, XVIII (1931), págs. 293-347. 
vida de los mortales. La doctrina deísta, no sistematizada, parece estar diluida en sus planteamientos ideológicos.

Uno de los académicos y miembro del tribunal, el duque de Villahermosa, opina que el canto de Trigueros «tiene realmente ideas poéticas excelentes; la fábula y la pintura de la destrucción de la armada es admirable», pero hay «algunas expresiones equívocas y triviales», por lo que «si fuera posible que se sujetase a las correcciones o advertencias que más despacio se podían hacer, pudiera concurrir al premio, pero en el estado en que se halla juzgo que no debe ser coronado el primero». Para García de la Huerta, amigo por entonces de Trigueros ${ }^{18}$, este poema «es el más digno de premio». En contra votaron Tomás Antonio Sánchez, Felipe Samaniego, Juan de Aravaca, Antonio Mateos Murillo, José Guevara Vasconcelos y Fernando Magallón. (Yo también hubiera votado en contra). Al final de estos comentarios irá la edición, por vez primera, de este poema inédito que, al mencionar el autor, confirma mi suposición con respecto al ejemplar de la Academia, cuyas variantes anoto al cotejarlos, en lectura reposada y minuciosa.

A estos poemas originales acompaña la traducción de los dos primeros libros de la Eneida, con 786 y 660 versos, respectivamente, de mano del mismo escribiente J. M. R. C. En la Biblioteca de Menéndez Pelayo se conservan otros fragmentos de esta traducción, pero la copia más completa es la de la Biblioteca Colombina (84-2-24), que contiene la traducción de los tres primeros libros y parte del cuarto, versión que hubo de rehacer después de un incendio, según comenta a Olavide en $1774^{19}$. Esta traducción de Trigueros es anterior a otras del XVIII, del padre Arnal (1782), de Vargas Machuca (1792) y de Tomás de Iriarte (1787). Menéndez Pelayo, que descalificó estos alejandrinos pareados, alabó su concisión.

A continuación incluye una carta dirigida al «M. R. P. fray Francisco Crespillo», remitiéndole una Introducción a la comedia Afectos de odio y amor, que se ha de representar en casa del Sr. Dn. Diego Villalón, en el recibo de novia que en su casa ha de celebrar con motivo del casamiento de su sobrino Dn. Antonio Villalón con la Sra. Dña. María Josepha Aranza, asistiendo a ella los parientes de los novios. El título de esta introducción teatral, referida a la comedia, es Amor cautivo y sin alas. Al final de la carta, con «mil expresiones al P. Prior», lleva su firma y rúbrica, suplicando modestamente que: «Si lleva alguna mentirilla enmiéndela $\mathrm{Vm}$. porque estoy cansado de hacer versos y no tengo paciencia para volverlos a leer y enmendar». No siempre fue así, desde luego, porque sus escritos suelen tener bastantes tachaduras y correcciones.

\footnotetext{
18 Francisco Aguilar Piñal, «Trigueros y García de la Huerta», Revista de Estudios Extremeños, XLIV (1988), págs. 291-310. Rep. en El académico Cándido M. ${ }^{a}$ Trigueros, págs. 159-170.

19 Vid. Un escritor ilustrado..., pág. 127.
} 
Otra carta, con su firma y letra, va remitida a persona desconocida, incluyendo catorce décimas satíricas contra un fraile, mal poeta, al que llama fray Cuchufleta, que escribió a petición de un anónimo corresponsal, al que pide que saque copia y destruya el original, para «no revelar mi nombre absolutamente a nadie... pues no me corresponde emplearme en tales vagatelas». Son décimas desconocidas. No lo es, en cambio, otro escrito satírico titulado El pleito del cuerno, entremés publicado años después en Córdoba ${ }^{20}$, «farsa cornuda compuesta por un cabrón», como dice uno de los manuscritos conservados en la Biblioteca Nacional de Madrid ${ }^{21}$. Todos los nombres de los principales protagonistas hacen referencia a los cuernos: «el abate Cornaquiny, el dómine Cornejo, el marqués del Cornil, doña Cornelia, doña Cornificia». Hacer burla y sátira de las infidelidades matrimoniales era, sin duda, frecuente en las tertulias y fiestas de sociedad, cotilleo de ratos de ocio en un siglo de creciente impudor sexual.

Dejo para el final dos escritos en prosa, de indudable interés. Uno se titula Adición al discurso sobre el número y celibato del clero, tema muy discutido en el siglo, al que Trigueros contribuye con este escrito de seis folios, en defensa del celibato clerical, que adicionan al cuerpo central del discurso. Sus cálculos numéricos sobre el aumento incesante de la población le sirven para contradecir a quienes pretenden suprimir el celibato eclesiástico, por la imperiosa necesidad de atender a los fieles en una nación católica: «los oficios del clero, que son otras tantas obligaciones que este tiene contraídas con la República, y cuyo desempeño es tan necesario en un País Católico, como el de los más precisos empleos civiles, exigen muchas personas». No sólo no es excesivo el número del clero, sino que es insuficiente, contra la opinión de algunos que lo pretenden reducir o incluso extinguir.

¿Cómo será posible que en cabezas de Filósofos y Políticos cristianos pueda caber la extravagante paradoxa de que nuestro actual clero destruye por su número a la Nación? Mui al contrario, deberá todo el que sea Filósofo, esto es, todo el que, libre de preocupaciones, use con acierto de su razón, admirar la sabia economía con que el clero ahorra a la Nación, en la práctica, más de la mitad de individuos que la especulación ha demostrado ser necesarios.

20 El pleito del cuerno. Obra graciosa del Poeta Filósofo. La da a luz un amigo del autor con la siguiente advertencia. Córdoba, Luis Ramos, s. a. Hay un ejemplar en la Biblioteca Pública de Córdoba y otro en el Instituto del Teatro de Barcelona.

${ }^{21}$ El pleito del cuerno. Farsa cornuda compuesta por un cabrón. Por Dn. Cándido M. ${ }^{a}$ Trigueros. Biblioteca Nacional de Madrid, mss. 14601/21 y 22, y 15955). Otra copia en la Institución Colombina de Sevilla (84-4-35). 
El celibato es motivo de otras reflexiones:

También probé en el cuerpo del discurso que el celibato de estos individuos no perjudica al bien de nuestro País; y para que mejor se entiendan algunas cosas que allí digo, quiero hacer aquí una sola consideración. Es de tal naturaleza nuestra fertilidad natural que, si Dios, ya con la brevedad de la vida, las enfermedades y otras causas físicas, ya por medio de obstáculos religiosos, morales y civiles, no huviera puesto un freno a la propagación posible, se destruiría precisamente el mundo por la superabundancia de su población.

Basándose en las demostraciones matemáticas de Euler, concluye que «está más claro que la luz del día que el celibato eclesiástico actual de nuestra nación, permaneciendo en el mismo número de personas, ni daña ni puede dañar a la población de nuestro País». La verdadera causa de la despoblación, a juicio de Trigueros, consiste en las dificultades sociales para contraer matrimonio, el abuso de los sirvientes celibatos, por efecto del lujo y de la corrupción de las costumbres. El cálculo final de personas vivas en un momento dado es de tal magnitud que «se destruirían y se comerían unos a otros». De aquí que «el celibato clerical, con su positiva consagración directa al mismo Criador, obra indirectamente el efecto negativo que necesita la subsistencia de la Creación ${ }^{22}{ }_{»}$.

Finalmente, otro ensayo sobre el teatro forma parte de este volumen, que sirve para completar la múltiple personalidad de este literato «ilustrado» (calificativo cuya significación no es unívoca entre los dieciochistas). Las cuatro páginas que siguen, Trigueros las dedica a comentar un discurso aparecido en la prensa con este interrogante: «¿No pudieran emplearse teatros purificados e inocentes en lugar de anfiteatros, que no pueden dexar de ser perniciosos?». El comentario es muy jugoso y no tiene desperdicio. Parece un borrador que nunca llegaría a publicarse, con varias correcciones de última hora, sin fecha ni firma, pero anterior a 1785. Habrá que recordar que Trigueros, a poco de llegar a Madrid, interviene en la polémica suscitada en la prensa por los partidarios de uno y otro bando teatral $^{23}$, defendiendo las mismas ideas de un teatro «ilustrado», necesario para la «instrucción pública, en el qual, aprovechándose de nuestras propias flaquezas y pasiones, se combaten nuestros errores por el medio que más se puede pegar a nuestra naturaleza, por ser el más análogo con nuestro corazón».

${ }^{22}$ Con este inédito descubierto, queda despejada la duda de F. Sánchez-Blanco sobre la autoría de Trigueros de las «Reflexiones filosóficas y políticas sobre si el estado eclesiástico que tiene la nación española puede perjudicar a su población», artículo aparecido en el periódico La Espigadera en 1791. (Cfr. Francisco Sánchez-Blanco, El Absolutismo y las Luces en el reinado de Carlos III, Madrid, Marcial Pons, 2002, pág. 378.)

23 Francisco Agullar Piñal, «La polémica teatral de 1788», Dieciocho, 9 (1986), págs. 7-23. 
Terminada la redacción de este artículo, recibo la sorprendente noticia de la aparición en el mercado de otro manuscrito trigueriano, esta vez texto unitario, encuadernado en pasta española de la época, con lomos dorados, que contiene la Vida de D. Agustín de Montiano y Luyando. Por D. Cándido María Trigueros, de la Real Academia de Buenas Letras de Sevilla. Año de 1770. Es un volumen de 232 páginas, más la portada, escrito con esmero por amanuense, pero rubricado al principio y al fin por el propio Trigueros, que así lo autentifica, corrigiendo las erratas del escribiente.

La pulcritud de la copia y lo que el autor anota al final del texto parecen indicar con claridad que estaba destinada al amigo de ambos Eugenio Llaguno, prohombre del reinado de Carlos III, a quien sugiere que publique esta biografía de su gran amigo, ya que «mejor que nadie conocía el genio del autor». No por interés ni por vanidad, sino «para aprovechamiento público». Sería de agradecer que la Real Academia de la Historia, institución de la que Montiano fue su primer director, atendiese a los deseos de Trigueros, que el alavés Llaguno y Amírola, condecorado con el Toisón de Oro, no pudo hacer realidad en los ocho años que le quedaban de vida, pues vivió unos meses más que Trigueros. Aunque lo he tenido en mis manos, no he podido leer completa la biografía, que supongo más que elogiosa del amigo de juventud. Debo añadir que en la cabecera de la portada hay una nota escrita a lápiz que dice: «Granada, 30 de setiembre de 1887». Por ahí ha de venir la pista sobre su anterior propietario.

Hasta aquí la noticia y resumen del contenido de estos desconocidos volúmenes manuscritos, cuya recuperación puede ser de gran interés para la investigación literaria del siglo XVIII, y en especial para el polígrafo Cándido María Trigueros. A continuación, aprovecho estas páginas para editar el poema inédito incluido en el primer volumen, sobre Las Naves de Cortés. Poema épico en un Canto. Que no ganó el premio propuesto por la Real Academia Española en la Gazeta de Madrid del Martes 7 de Octubre de 1777. Por Dn. Cándido M. ${ }^{a}$ Trigueros, de la Real Academia de Buenas Letras y de la Real Sociedad Patriótica de Sevilla. Al final, hay una nota que dice: «Copiólas J. M. R. y C. Año de 1779, a 22 de Diciembre». Es, por tanto, una copia del original conservado en la Real Academia Española (Premios, 1778), cuya portada, después del título, aclara que se presenta «Para concurrir al premio de Poesía propuesto por la Real Academia Española, en la Gazeta de Madrid del martes 7 de octubre de 1777».

He cotejado ambos manuscritos para poner de relieve sus variantes, aunque algunas se repiten sin mayor trascendencia que la fonética, como el uso de la 
letra «s» por el copista andaluz, en vez de la «z» de Trigueros («Cacique» por «Casique»), el empleo de la «y» del copista por la «i» latina del autor («Hoy» por «hoi», «muy» por «mui», «Rey»por «Rei») o la confusión de la «v» de Trigueros por la «b» del copista («embidia» por «envidia») y la «g» por «j» («parage», «protege», «vagel», de Trigueros). La impresión que deja la lectura y cotejo de ambos manuscritos es que el desconocido amanuense ${ }^{24}$ se tomó algunas «libertades» al copiar el original. Por ejemplo, acepta las correcciones del autor que constan en el original (tachadas), pero se permite corregirlo en otras palabras que no le parecen adecuadas, y las sustituye por otras de propia cosecha (sin tachar), pienso que sin autorización del autor. Lo que remite a la idea, ya muy aceptada, de que, desde la época medieval, los textos literarios carecían de derechos de autor y cada cual los podía modificar a su gusto y mejor criterio. Todavía en el siglo XVIII.

A todo precede, a modo de advertencia, lo escrito por Aristóteles en el capítulo IX de su Poética:

Manifiesto está, por lo dicho hasta aquí, que el oficio de Poeta no es contar las cosas que fueron, sino las que podían haver ${ }^{25}$ sido, probable o necesariamente; porque el Historiador y el Poeta no solamente se diferencian por escrivir en prosa, o en verso; pues podían ponerse en verso las obras de Herodoto, sin que por eso dexasen de ser una Historia, ora estuviesen en versos, ora sin ellos: diferénciase el Poeta del Historiador en que este refiere las cosas como acontecieron y aquel como devían acontecer, por lo qual la Poesía es más filosófica y más laudable ${ }^{26}$ que la Historia.

El Autor de este Poema ha tenido presente este juicioso precepto de Aristóteles, al disponer la Fábula que ${ }^{27}$ parecía convenir mejor ${ }^{28}$ al asunto propuesto por la Academia, pero no ha querido valerse de hechos inventados. La Ynvención y Ficción, indispensable en la Poesía épica, solamente ha servido para hacer sensible la imaginación. Ordenado el todo y dispuesto en un sistema o Fábula, el Poeta ha hecho que se vea como de bulto, y en acción, y movimiento lo que el Historiador da motivo para imaginar con quietud y fríamente: ha procurado pintar, aun al referir, y en lo que se refiere ha querido escoger solamente lo que juzgaba que convenía a la Pintura.

\footnotetext{
24 No acierto a descifrar a qué persona corresponden las iniciales J. M. R. y C.

25 Respeto la ortografía original, aunque resuelvo las abreviaturas y agrego los acentos, como es costumbre.

26 La primera redacción decía «seria», pero Trigueros tachó este adjetivo y lo sustituyó por «laudable» remitiendo al original griego. Resulta sorprendente que un escrito que opta a un premio se pueda presentar con tachaduras y sustitución de palabras y aun de versos, en revisión de última hora.

27 En el original «le parecía».

28 Faltan en el original las palabras «mejor»y «asunto»; sustituyen al tachado «hecho».
} 


\section{Las naves de Cortés \\ Poema épico en un canto}

Nil actum reputans, si quid superesset agendum.

Lucan.

Para concurrir al premio de Poesía propuesto por la Real Academia Española, en la Gazeta de Madrid del martes 7 de octubre de 1777.

\section{Octavas}

1

Di, Musa, cómo fueron abrasadas

Por el Gefe Español más animoso

Las Naves, que en el mismo ser quemadas

Dieron a España el triunfo más glorioso:

Cuenta el valor por quien, aniquiladas,

Anegaron el miedo pavoroso,

El antípoda Imperio destruyeron

Y a España y su Fe santa un Mundo dieron.

2

Tú, que inspiraste versos eminentes

De la Grecia y de Italia a los Cantores,

Dicta esta vez en rimas excelentes

Con motivo mayor cantos mejores:

Y haz que en aplauso de invencibles Gentes

Con agradables tonos y loores,

La hazaña, que a la Gloria satisfizo,

Cante también como Cortés la hizo.

3

En la empresa mayor HERNÁN ${ }^{29}$ pensaba

Que jamás las naciones sospecharon,

Cuya idea feliz sobrepujaba

Quanto los hombres nunca imaginaron:

Y el Puerto, y Ciudad breve, que fundaba.

29 Sustituido por «Cortés» en el original. 
Donde sus pocos Héroes se albergaron ${ }^{30}$, Quería que principio y basa fuera

Del Imperio mayor que el orbe viera.

4

Otro en arrojo tal no pensaría ${ }^{31}$,

Contento con lograr digna victoria ${ }^{32}$,

O fundar corto Estado, que podría

Perpetuar su nombre en la memoria;

Cortés piensa en lo sumo: Cobardía

Juzgaba el poner lindes a la Gloria:

Y aun la hazaña más grande y admirada,

Si algo resta que hacer, piensa que es nada.

5

Tal facción ${ }^{33}$ en la mente rebolviendo

Disimulaba el Adalid hispano,

Y las cosas trataba ${ }^{34}$, que van viendo,

Ya con los suyos, ya con el Yndiano.

Zempoallan, su amigo ${ }^{35}$, conociendo

De su aliento el poder, y de su mano,

Miraba quán buen medio se ofrecía

Para lograr venganzas, porque ardía.

6

Era el Yndio feroz y poderoso,

Dotado de doblez y astucia suma,

Y enojado vivía y envidioso

De la Gloria y poder de Montezuma ${ }^{36}$;

Mas pretextos ${ }^{37}$ buscaba de quexoso,

Porque CORTÉs su embidia no presuma,

\footnotetext{
30 Cortés fundó una pequeña villa, sobre la margen derecha del río Csatzacoalco, a la que dio el nombre de Espíritu Santo, en la costa meridional de México.

31 «Otro con menos se contentaría».

32 «Aspirando no más que a la victoria».

33 «empresa».

34 «trataba las cosas».

35 Zempoallán era la capital de una tribu, los «totonacos», que fueron los primeros aliados de Cortés, y Trigueros se toma la licencia de nombrar con este nombre al jefe tribal.

36 Moctezuma, emperador de los «mexicanos».

37 «pretestos».
} 
Y viéndole en seguir su empresa fixo, Quiso alentare más, y así le dixo.

«Si tú, que gloria buscas, te miraras Por el sobervio México oprimido, Menos en las empresas te pararas A qué de largos climas has venido; Pero si más lo piensas, y te paras, Quizá suspirarás arrepentido

De innumerables ${ }^{38}$ yndios hecho presa

Por no usar, hoy que es tiempo, la sorpresa ${ }^{39}$.

8

»Yo triste, que sufrí por muchos años

Del fiero Montesuma la injusticia.

Conosco dónde llegan sus engaños, Y quál es el poder de su malicia:

Participantes son de tales daños, Que dan a su maldad grata delicia, $\mathrm{Y}$ en que a su vanidad suelta los diques Mil abatidos Yndios y Casiques.

\section{9}

»Todos, y el Tlax[c]alteca poderoso, Que siempre al Mexicano fue terrible, Te ayudaremos con tesón gozoso

Para domar un Monstruo tan temible: Queremos más servir tu Rey glorioso Que un tirano temer aborrecible: Senos la guía tú para que obremos, Y ni aún al universo temeremos».

Dixo: Y CORTÉs, con rostro muy afable, diado»).

«De innumerables» Yndios («hecho presa» sustituye en el original al tachado adjetivo «ase-

39 En el original, tachado: «Por no haver la sorpresa aprovechado». 
Mostró que sus ofertas no dudava, Y que, para una empresa tan loable Las medidas y medios maduraba:

Que siempre la prudencia es saludable, Y en ella más que en armas confiaba.

En fin, que siempre hai tiempo de obrar fuerte, Y acabó su respuesta desta suerte.

\section{1}

«La postrer gota de la sangre honrada,

Que anima nuestras venas españolas,

Con valor y contento derramada,

Corriera por vengar tus quexas solas:

Una vez la amistad afianzada,

Ni largas tierras ni furiosas olas,

Defenderán a nuestros enemigos

Quando hai que redimir nuestros amigos.

12

»No nos trae de climas tan lexanos

Otro interés, en tal trabajo fiero,

Que el de estender a todos los humanos

La Religión y Culto verdadero ${ }^{40}$ :

La Religión, que mira como hermanos

Todos los hombres, cuyo amor sincero

Se ocupa ${ }^{41}$ en aliviar al afligido

Y en dar la libertad al oprimido».

\section{3}

Si tal es vuestro fin (interrumpiendo

Dixo Zempoallan), en parte alguna

Debéis hacer triunfar con más estruendo

La Religión que os da tanta fortuna;

Aquí la Humanidad yace ${ }^{42}$, gimiendo,

Ya el culto de un Dragón, ya de la Luna,

\footnotetext{
40 El clérigo «ilustrado» que era Trigueros convierte al conquistador extremeño en misionero católico Un poco más adelante califica a Cortés de «hechura» de Dios.

41 «se emplea».

42 «vive».
} 
La sangre de sus hijos vierte el Padre,

Y canta, y lo celebra, hasta su Madre.

Siempre cruel, el duro Mexicano

Sirve a Tescalipuca ${ }^{43}$, Deidad fiera,

Y renunciando quanto suena a humano

Se complace en la acción más lastimera:

Su estatua ensangrentaron por su mano

Sin que su corazón se estremeciera,

Al amasar, en furias siempre fixos,

La sangre y corazones de sus hijos.

Al escuchar, CORTÉs se enternecía, Y en lágrimas sus ojos arrasaba, Y le dixo al Casique con voz pía, Entre heroicos sollozos que ocultaba:

«Dexa, Zempoallan, la cuenta impía

De un culto que en el alma se me clava:

Tu voz a la venganza me enfurece,

Mas, no quiero negarlo, me estremece.

16

» ¡Ah!, déxame ya solo, que no quiero

$\mathrm{Ni}$ aun oír un tenor tan inhumano

Mientras el solo Culto ${ }^{44}$ verdadero

No logro persuadir al Mundo Yndiano;

Mi Dios, aunque suave, es justiciero:

Las victorias tendremos por su mano ${ }^{45}$;

Él hará que te rindas, y te asombres,

Quando, al vengarse a sí, vengue a los hombres».

43 Tezcatlipuca era el nombre del ídolo o deidad a la que adoraban los mexicanos en la Casa de los Ídolos, que Cortés purificó y consagró a Nuestra Señora de los Remedios. Estaba situada enfrente del palacio de Cortés, donde hoy se levanta la catedral de México. En la obra The World or the present state of the Universe (1810) se inserta un grabado de Copper, con la imagen del ídolo, que aparece en actitud guerrera y desafiante, entre huesos y calaveras.

44 «el culto solo».

45 «de su mano». 
Dixo: Y Zempoallan partió al momento,

Y con él los demás, que allí presentes

Hasta entonces pendiendo de su acento,

Escucharon sus pláticas ardientes:

Sólo CORTÉs reprime su tormento,

Y aunque le aquexan lástimas ve[he]mentes ${ }^{46}$,

No permite a su pecho que suspire.

Pide su auxilio a Dios, y que le inspire.

18

Dios en tanto miraba desde el Cielo,

Con ojos complacidos ${ }^{47}$, a su hechura,

Y mil Santos mostraban su gran celo

En torno de su trono y su luz pura.

Todos aprueban tan constante an[h]elo,

Y desean su bien y su ventura;

Mas a los otros ex[c]edió rogando

El que dio a CORTÉs nombre, el Real Fernando ${ }^{48}$.

«Veo (dixo) Señor ${ }^{49}$, en CORTÉs solo

Mi Patria y Religión ${ }^{50}$, mi celo miro,

Y con quánto valor al otro polo

Quiere llevarla, y su tesón admiro:

De Satán la maldad y cruel dolo

Le asesta de la enbidia el doble tiro;

¡Ah! No logre su fin: dadle victoria,

Consiga el triunfo él, y vos la gloria.

20

»Una empresa por vos solo inspirada,

Que sin vos ni aun ser pueda concebida,

Llegue por fin a ser perficionada

Con vuestra santa diestra protexida:

No puede ser sin vos executada

46 «vêmentes».

«complacientes».

48 «con plática como esta el Real Fernando».

49 «Veo, Señor, mi Patria».

50 «Mi Religión en él». 
Acción tan sin ejemplo, y nunca oída:

Consígala una vez, y admire el Hombre,

Quánto aun el Hombre puede en vuestro nombre.

\section{1}

»Vos vuestro amparo disteis a mi diestra, Y yo con él lancé del Reino hispano La árabe Yrreligión torpe y siniestra, Que imponía el poder del Africano; Hoy otra Irreligión feroz se muestra, Que os roba todo el Mundo mexicano; ¡Oh! Proteged, gran Dios, acción tamaña, Y haga que triunféis vos, la gran España».

\section{2}

Calló: y los demás Héroes celestiales Sus reverentes votos repitieron;

Todos, con celo igual, ansias iguales, De CORTÉs las venturas promovieron: Se interesaba el Cielo en dichas tales Por los bienes que dellas se siguieron: Y no omitían sus solicitudes La Religión, el Culto y las Virtudes.

\section{3}

Dios, al ver repetir tales an[h]elos, En sí mismo feliz se complacía, Y difundió su gozo por los Cielos Concediendo a su ardor lo que pedía: Decretó que CORTÉs, con sus desvelos, Efectuase $l^{51}$ que apetecía, Y que, para hacer cierta su esperanza, Le fuese a sostener la Confianza ${ }^{52}$.

\section{4}

La Confianza al punto, desde el trono

51 «Efectuase el fin».

52 Uno de los dioses antropomórficos inventados por Trigueros, presentes en todas sus composiciones épicas, aquí aumenta con el Temor y la Envidia, la Quietud y el Sueño, que le habla por la noche para incitarle a quemar las naves. 
Del Alto Criador, voló a la Tierra, Para hacer, de CORTÉs en justo abono,

Al Temor y la Embidia eterna guerra.

Vio a esta, que navega con encono,

Y desde Cuba a Veracruz aferra;

Mirola con desdén desde lo sumo

Y con mirarla, convirtiola en humo.

25

Era en tanto de noche: los mortales

Del diurno trabajo fatigados,

Olvidavan los bienes y los males,

En sosiego agradable sepultados:

Los astros ocultaban sus fanales

De alumbrar sin ser vistos ya cansados:

Reina en todo el silencio más profundo;

La Quietud con su manto cubre el Mundo.

26

Llega hasta Veracruz la Confianza;

Dobla sus alas ya sin hacer ruido,

E infundiendo en los pechos esperanza,

Visita el Pueblo en sueño sumergido:

Quando ya en los Soldados se afianza,

Y está todo español fortalecido,

Toma diestra del Sueño la figura

Y [h]acia coRTés callada se apresura.

\section{7}

Se acerca, y en sus brazos le fomenta,

Lanzándose en su seno gratamente:

Su constancia feliz de nuevo alienta,

Haciéndose señora de su mente:

Su esfuerzo y su valor crece y se aumenta

Quando en su corazón tal huésped siente:

Ella apenas le vio constante y fijo ${ }^{53}$,

Abrió su boca amable, y así dixo.

53 Aquí usa la letra «j» y en el verso siguiente la «x». Indeterminación ortográfica propia de la época. 
«¿Qué te paras, HERNÁN"54? Grandes acciones Las logra sólo el grande atrevimiento:

Saber aprovechar las ocasiones Es del valor la prueba, y del talento.

No te detengas más en reflecciones ${ }^{55}$;

Arma tus españoles al momento,

Acomete en su Corte a Montesuma,

Llena a España y a ti de gloria suma.

\section{9}

»La empresa es grande, inmensa y arriesgada

Para qualquiera que corTés no sea;

Quizá será de alguno murmurada,

Que con menos valor que tú $10^{56}$ vea;

Pero por si la tropa amedrentada

Fuere capaz de cobardía fea,

Fuérzala tú a tener mayor denuedo,

La fuga impide, y quitarasla el miedo.

\section{0}

»Los famosos vageles que alas fueron

Con que volasteis a tamaña empresa,

No estorven el blasón a que os trajeron,

Hoy que tenéis las manos en la presa:

Quémalos, que ya al fin ${ }^{57}$ mayor sirvieron;

Nasca vuestro valor de su pavesa,

Y el que fuere cobarde en tal partida,

Lidie a lo menos por guardar la vida.

\section{1}

»La Desesperación da un valor fiero.

Huye los canes, tímido, el venado ${ }^{58}$, Y mientras puede huir, corre ligero;

Mas acomete en viéndose acosado. 
Quema en $\operatorname{las}^{59}$ Naos el huir postrero, Y no será cobarde ni un soldado:

La Inacción y el Temor en ellas quemas;

Espera en Dios, emprende, y nada temas».

\section{2}

Dixo, y despareció. CORTÉs, al punto,

Despierta, y libre ya del grato sueño,

Mira el Pueblo en silencio, qual difunto,

Y de la noche huir el negro ceño:

Recoje su valor para un asunto

Sin exemplar, y del mayor empeño:

Duda, se para, al fin, determinado,

Quiere que luego sea executado.

\section{3}

Busca las gentes en que más confía,

A media voz les dice, y al oydo,

La gran hazaña que a su esfuerzo fía;

Que, al robar gloria, teme ser sentido.

Se pasman, más no duda su osadía;

Callar y obedecer es su partido:

Parten, y sin hablar, mechas ${ }^{60}$ encienden

Van a las Naves ${ }^{61}$, y la acción emprenden.

\section{4}

La Aurora, en tanto, luces derramaba

Con su dorada ${ }^{62}$ diestra sobre el Orbe,

Y el soldado en silencio descansaba,

Sin que cuidado alguno se lo estorbe:

Con suave rocío se regaba

Toda planta, que en él su vigor sorbe:

Vio conTÉs a lo lexos un gran fuego,

Y a ver qué fuese, armado partió ${ }^{63}$ luego.

\footnotetext{
59 «tus Naos».

60 «teas».

1 «Naos».

62 «rosada», que no está tachada en el original. ¿Por qué toma el copista la decisión de cambiar el adjetivo? ¿Con o sin autorización del autor?

63 «fue allá».
} 
Era Zempoallan, que no dormía:

¡Ah! ¡Que la Envidia ${ }^{64}$ oculta no reposa!

De Montesuma el mal apetecía,

Y al Cielo hacía súplica horrorosa:

A sus aerios ${ }^{65}$ Dioses ofrecía

De petun y copal ${ }^{66}$ nube olorosa,

Quemándolas por él en pipas cinco

Soldado y sacerdote Arapasinco.

\section{6}

Llega CORTÉs, se informa y le reprende. «¿Quál ceguedad (le dice sin reparo)

Te entrega a un Dios que en vano te defiende?

¿De qué, dime, hasta aquí sirvió su amparo?

Si triunfa Montesuma, si te ofende,

¿Por qué no olvidas ese culto raro?

Sólo puede cumplir acción tamaña

El poderoso Dios que adora España».

\section{7}

Así dixo, el gran fuego derrivando

Que a honor del falso Dios ardido havía:

Zempoallan, venganza deseando,

En nuevo ardor por ella se encendía.

$\mathrm{Y}^{67}$ también a tu Dios iré adorando

(Dixo) si es fuerte en la defensa mía:

Y detestando el Dios que no le ampara,

Rompió en las Pipas el altar y el ara.

\section{8}

Mientras esto los Genios infernales

Contra la Religión, Consejo hacían,

Y destruir las miras celestiales

64 De nuevo la indefinición ortográfica: unas veces «envidia» y otra «embidia».

65 Por «aéreo», en su significación figurada: fantasmal, inmaterial, sin fundamento.

66 Nota del autor: «Tabaco en rama y goma aromática: de uno y otro usaban en vez de incienso los Yndios». El original añade: «en sus sacrificios, en vez de incienso».

67 «O». 
Con ocultas astucias emprendían ${ }^{68}$ :

Ansiaban de los nuestros por los males,

Y como sus venturas percibían ${ }^{69}$,

Despavoridos todos acudieron

Al punto que las Naves arder vieron.

39

«¿Qué pretendes ${ }^{70}$, corTés?» (exclamó airado

El Príncipe Satán), ¿̨con qué segundo

Atrevimiento, de hombre no estrenado,

Piensa turbar nuestro dominio inmundo ${ }^{71}$ ?

En un Mundo de gloria se ha llenado,

Le ha colmado de gloria el otro ${ }^{72}$ Mundo;

¿No está seguro dél mi duelo eterno?

¿Quiere vencer Hernán ${ }^{73}$ aun al Ynfierno?

40

»Vedle allí derrivar nuestros altares,

Ved que Zempoallan ya titubea:

Hizo Cristianos Yndios a millares,

Y emprende qué sé yo qué nueva idea:

Yo veo en esas llamas mis hazares;

Ympedido su estraño intento sea:

¡Ah! Si no contenemos su osadía,

Pondrá fin a la Yndiana Idolatría».

41

Dixo: Y en mil ideas divididos,

En recursos mui vanos ${ }^{74}$ derramados,

Mostraron en ${ }^{75}$ consejos aturdidos

Que CORTÉs los tenía atolondrados.

Al fin, en una idea son unidos,

$\mathrm{Y}$ en un ruin pensamiento concertados,

«pretendían».

69 «entendían». Ni este verbo ni «pretendían» (nota 68) están tachados en el original.

«pretende», en tercera persona verbal.

«imundo».

«nuevo».

«Cortés vencer».

«En vanos pensamientos».

«con». 
Que sin duda gran mal causado hubiera, Si el Cielo al gran varón no protegiera.

\section{2}

Hai un horrendo Monstruo femenino, Que hoy de Boston a Londres volar suele, Cuyo sangriento ardor, y desatino,

Sólo quando ve paz se quexa y duele: $\mathrm{Su}$ deseo es turbar el amor fino, Y su efecto que el Orbe arda y se asuele, Pereciendo la unión y la concordia: Esta Fiera se nombra la Discordia.

Su amparo los Precitos escogieron; Viéronla ${ }^{76}$, sus zozobras la contaron, Nuevas espuelas a su ardor pusieron, Y su fácil rencor determinaron: Apenas sus deseos la ${ }^{77}$ dixeron, Y los grandes motivos la explicaron; Voló [h]acia Veracruz con ansia avara A destruir lo que CORTÉs obrara ${ }^{78}$.

\section{4}

Mientras ella, las gentes despertando, Sutiles asechanzas disponía, Por cuyo astuto medio iba pensando Deshacer $^{79}$ lo que el héroe pretendía: Y él con Zempoallan de Dios hablando, En su Fe verdadera le instruía:

A los Reales llegó Titzapazinco

Que al gran corTés buscaba con ahínco.

\section{5}

Era el tal un Casique poderoso, Primero por el Héroe derrotado,

76 «Y sus grandes», sin tachar.

77 Se aprecia aquí el laísmo de Trigueros.

78 «pensara», tachado.

79 «Deshacer». 
Que ya de Montezuma muy quexoso ${ }^{80}$

Havía su partido abandonado:

Con él Chiahutlan ${ }^{81}$, Yndio animoso,

Del gran poder de México acosado,

Venía [h]acia CORTÉs con esperanza

De lograr por sus armas la venganza.

46

Recívelos HERNÁN ${ }^{82}$ muy [h]alagüeño

Y les cuenta el poder del grande Carlos:

De Montesuma pinta ${ }^{83}$ el duro ceño

Y procura mejor asegurarlos:

Ruéganle ${ }^{84}$ que los rumbos de un empeño

Que es tan sin exemplar, quiera contarlos:

Ofréceles decirlo brevemente,

Y penden de su voz gustosamente.

«Juntos en Huanganigo ${ }^{85}$ mis soldados;

Que no es justo ofender vuestros favores,

Gastando tiempo en referir los hados,

Que me ofrecieron hechos anteriores:

Ya todos los vageles aprestados,

Órdenes repartí a los superiores;

Levé el ancla dispuesto a los hazares,

Y en el nombre de Dios barrí los Mares».

48

»Mas apenas al golfo ${ }^{86}$ entrado havía

Los Genios enemigos de la España

Perturbaron la luz del mediodía

Con tempestad y furia muy estraña:

El Sol se recataba y escondía:

80 Aquí, como en otras ocasiones, respeta el copista la «X» gutural de Trigueros.

${ }_{81}$ Chiahutla es un municipio mejicano.

82 «Cortés». ¿Cómo se explica el atrevimiento del copista que cambia incluso el nombre de Cortés, usado siempre por Trigueros, por el nombre de pila «Hernán»?

83 «dice».

84 «Pídenle» en el original, sin tachar.

85 Tachado en el original: «Huanigo».

86 «Golfo», con mayúscula, en el original. 
Soltó el viento sus alas y su saña:

Se mece el mar y lanza tanta niebla

Que nos cubre de sombra y de tiniebla.

49

»Afana el oficioso Marinero,

$\mathrm{Y}$ a tiento por costumbre maniobra:

Se altera más el elemento fiero,

El Noto arrecia y brío nuevo cobra:

Las olas braman, cruge el mastelero ${ }^{87}$;

En medio de tal ruido y tal zozobra

Truena a babor, [h] acia estribor retruena, Y el relámpago alumbra la faena.

\section{0}

»No os quiero referir quánto pasamos

En menudos pesares que tubimos;

Que quando aquí en quietud y en tierra estamos

No os puedo hacer sentir lo que sufrimos:

Por todo el ancho mar nos derramamos,

Y socorro ninguno dar pudimos

A un buque, el qual ${ }^{88}$ miramos deshacerse

$\mathrm{Y}$ entre las altas olas esconderse.

\section{1}

»Al fin, cansado el Noto de ofendernos, Mientras de padecer no nos cansamos, Bolvió la luz del día a socorrernos, Y otra vez el viaje concertamos:

Separados $\operatorname{los}^{89}$ Buques $^{90}$, y sin vernos, Poco a poco los once congregamos:

Tierra en muy breve tiempo descubrimos

$\mathrm{Y}$ a ella ansiosos ${ }^{91}$ las proas dirigimos.

\footnotetext{
al mástil mayor.

¿También entiende Trigueros de náutica? «Mastelero» es un mástil menor del barco de vela, sujeto

88 «A un vagel, que miramos», sin tachar.

89 «las».

90 «Las Naos», sin tachar.

91 «Y hacia ella».
} 
»Eran de Aquicamil, Yslas famosas,

Donde el fuerte Aguilar cautivo ${ }^{92}$ estaba;

Viéronle nuestras gentes muy gozosas,

Y él me contó el paraje en que me hallaba:

Zumail, de las Yslas poderosas

Es cabeza que a todos ${ }^{93}$ gobernaba;

En ella entramos, dueños nos hicimos,

Y Santa Cruz por nombre la pusimos.

\section{3}

»Otra vez a las olas nos fiamos

Y corrimos su riesgo y sus hazares:

Presto a Puerto Escondido ${ }^{94}$ divisamos,

Donde se minoraron los pesares:

Aquí los compañeros encontramos,

Que creímos despojo de los Mares,

Y con ellos estaba guarnecido ${ }^{95}$

El vagel que jusgamos sumergido.

\section{4}

»Saltamos a la tierra muy contentos,

Adonde una lebrela descubrimos,

Que acordó de Grijalva los alientos,

Pues ser rezago suyo conocimos:

Con ella por el bosque muy atentos

Las ásperas malezas recorrimos:

Y adquirí, en montería recreado,

Para cada vagel un gran venado.

\section{5}

»A la vela de nuevo nos hicimos ${ }^{96}$, Y en Tabasco surgiendo por su ría,

\footnotetext{
92 «esclavo», sin tachar. Efectivamente, Jerónimo de Aguilar estuvo cautivo en Yucatán.

93 «todas».

94 En la actualidad, Puerto Escondido es, según la propaganda turística, «un paraíso tropical, con increíbles playas y majestuosas vistas».

95 «guarecido».

96 «Otra vez a la vela nos hicimos».
} 
Al fiero Pontocan paz propusimos, De que intentó abusar su cobardía: Acometió emboscado, le vencimos, Que el Cielo castigó su astucia impía: Los suyos, admirando cien ${ }^{97}$ portentos, Quedaron derrotados, mas contentos.

56

»De tiempo immemorial ${ }^{98}$ los Yndios daban

A una sagrada Cruz culto profano:

Y viendo que los nuestros la adoraban, Nueva afición tomaron ${ }^{99}$ al Cristiano:

Fácil nos fue mostrarles quánto erraban, Y nuestra Fe enseñar al Pontocano:

Nuevos refrescos dellos recivimos, Y la Fe, y Religión y a Dios les dimos.

57

" ¿Pero, para qué os canso? Muy molesto

Fuera una lista hacer de mis hazares:

Ni tenemos hoi tiempo para esto,

Ni se puede ignorar lo que dan Mares.

A Calchicoria fuimos, y muy presto

Se trocaron los gustos en pesares:

Acudionos Teudill con gracia suma;

Mas hízole cambiarse Montesuma.

58

»Retireme, fundé esta Fortaleza:

Busqué a Zempoallan, hallele amigo,

Socorrionos muy fina su largueza,

Y dexé de temer todo enemigo:

Chiahutlan después, con gran franqueza,

Nos acogió: en su Estado fui testigo

De quán avaro era el Mexicano;

Mas esta vez al menos lo fue en vano.

9 «mil».

98 «imemorial».

99 «tomaban». 
»Tú al fin, Titzapazinco, dél movido,

La guerra sin consejo nos hiciste:

Con harto dolor mío, acometido

$\mathrm{Fui}^{100}$ causa de las penas que sufriste:

Pasaste al fin a amigo de vencido,

Y el partido mejor así elegiste:

Libertarte esperaste del tirano,

Y hoy lo lograréis todos por mi mano.

\section{0}

»Hoy mismo...». Quando aquí corTÉs llegaba

Se oyó un tumulto y gran vocinglería,

Polvo espeso en el campo se elebaba,

Y confusión de voces mil se oía:

Pasmose todo Yndiano, que ignoraba

De dónde el caso estraño le venía;

Pero Cortés, aunque ${ }^{101}$ de enojo lleno,

Caminó [h]acia la playa muy sereno.

\section{1}

La Discordia, entretanto, astuta y fiera,

Cubierta siempre de invisibles tocas, Ympedía que el vulgo más durmiera, Turbole y le inspiró sus ansias locas.

Embioles la Fama vocinglera,

Monstruo de mil oídos y mil bocas,

Que, encendiendo sus ánimos en iras,

Les contó una verdad en mil mentiras.

62

«El heroico CORTÉs, si verdad fuera ${ }^{102}$

Lo que la Fama entonces les decía, Quería que su gente pereciera ${ }^{103}$, 
Y entregarse con todos proponía ${ }^{104}$ :

Porque avisar a Carlos no pudiera ${ }^{105}$

El Español, las Naos encendía:

Con Montezuma el hecho consultaba, Y reinar con él solo meditaba».

63

Todos, al oyr ${ }^{106}$ tal, alborotados

Con el riesgo y el susto sorprendidos, Corren por la Ciudad amotinados, $\mathrm{O}$ van $[\mathrm{h}] \mathrm{acia}^{107}$ la Playa mal vestidos:

Ya lo recorren todo muy armados, Ya saltan a las Naves atrevidos,

Amenazan, se quexan, gritan, braman, Venganza piden y Justicia claman.

64

Aquí suena furor ${ }^{108}$, allá clamores, Mésclanse la osadía y los gemidos; Las mugeres redoblan los horrores Con sus inconsolables alaridos: Óyense y no se entienden sus ardores, Van, vienen, buelven, tornan confundidos; Entretanto las naves abrasaban ${ }^{109}$, Y el horror con sus llamas atizaban ${ }^{110}$.

65

Qual peñón en mar alta bien clavado ${ }^{111}$ Siente airadas las olas sin moverse, Así corTés, con rostro mesurado, Oye el tumulto sin estremecerse. Miróle la Discordia con cuidado

\footnotetext{
104 «pretendía», sin tachar.

105 «pudiese», sin tachar.

106 «oír», sin tachar.

107 «hasta», sin tachar.

08 «el furor», sin tachar.

109 «más ardían», sin tachar.

110 «encendían», sin tachar.

111 «el peñón en alta mar clavado», sin tachar.
} 
Y tubo tentaciones ${ }^{112}$ de esconderse;

Mas, por lograr al fin lo que desea ${ }^{113}$,

Así a Vela hizo hablar su rabia fea ${ }^{114}$.

66

"¿Qué pretendes, CORTÉs, mal dirigido ${ }^{115}$ ?

¿Mandas quemar las naves enojado

Porque a lograr mil triunfos te han traído

Y de peligros ciento te han librado?»

Gutierre, desde atrás, enfurecido,

Con acento clamó, desmesurado:

"¿Quieres que sin recurso nos quedemos?

¿Por darte a ti placer ${ }^{116}$ pereceremos?».

\section{7}

«Sí (dixo firme HERNÁN) ${ }^{117}$, quiero forzaros

A que oséis dominar a Montezuma,

A morir o vencer quiero enseñaros,

Y a lograr muerte honrosa ${ }^{118}$, o gloria suma:

Sígame con valor y sin reparos

Quien de Cristiano y Español presuma:

Ved allí sano un Buque ${ }^{119}$, el que olvidare

Su Religión y Rey, en él se ampare».

\section{8}

Qual el que escucha trueno repentino

Y mira ante sus pies el rayo alado,

Así del gran Gutierre el desatino,

Y de Vela el vigor quedó pasmado:

La Confianza, con esmero fino,

Traxo al Patriotismo recatado:

\footnotetext{
112 «y pensamiento tubo de», sin tachar.

113 «el fin que la desvela», sin tachar.

114 «Le envió el más resuelto, que era Vela».

115 «(dixo atrevido)», sin tachar.

116 «gusto a ti», sin tachar.

117 «(les dixo Cortés)», sin tachar.

118 Tachado, «breve muerte».

119 «un vagel sano», tachado.
} 
El ruido y rumor luego se acaban ${ }^{120}$, Y todos, suspendidos, escuchaban.

\section{9}

Gutierre dio un suspiro, otro dio ${ }^{121}$ Vela, Y corren a la Nave que no ardía:

Cada qual por mirarlos se desvela, Y con los ojos fixos atendía:

En vano la Discordia al fraude apela, Y ex[c]itarlos de nuevo pretendía:

Corren el Patriotismo y la Esperanza, Y se lanza en los más la Confianza.

70

Vela y Gutierre salen del Navío, El qual, quanto salieron, zozobraba: Se arrojan donde ven al Héroe pío, $Y$ el tropel todo en ellos se fixaba. Ya barrenado, al elemento frío Se sumerge el vagel que nos ${ }^{122}$ restaba: (Dice Vela): «Perdóname, y si quieres, Llévame, y venceré donde estubieres».

71

Qual, quando a un orador muchos oyeron, Y de sus persuasiones se llevaron, Todos a grandes gritos aplaudieron, Y la feliz e[n]mienda celebraron.

La Discordia y los Monstruos luego huyeron Y hasta su negro abismo no pararon; Victoriosa, por fin, la Confianza, Coloca en todo pecho la Esperanza. 72

Todos sin susto ${ }^{123}$ ven cómo perecen

\footnotetext{
120 «cesaban», tachado.

121 «y otro Vela».

122 «la nave que», tachado.

123 «alegres», tachado.
} 
Las Naves, en que huir quizád ${ }^{124}$ pudieran, Si en los dudosos casos que se ofrecen,

Alguna vez ${ }^{125}$ cobardes no vencieran:

Menguan los Buques y las lamas crecen;

Mas antes que ceniza se bolvieran,

Tocó la Confianza el feliz ${ }^{126}$ humo

$\mathrm{Y}$ ver hizo ${ }^{127}$ en su seno un pasmo sumo.

\section{3}

Cien grupos en el humo se quaxaban,

Y como en claro espejo se imprimían:

Las muy gloriosas llamas alumbraban

$\mathrm{Y}$ venturosos triunfos todos vían:

Sus futuros trofeos reparaban,

Con lo qual sus alientos recrecían:

La Confianza les prestó sus ojos:

Sólo vieron ya dichas, y no enojos.

\section{4}

Ya de Zempoallan acompañados,

Ven que de cien Caciques muy servidos,

Son por Sicuchimati regalados

Qual Dioses protectores recividos:

Ya van a Castilblanco ${ }^{128}$ muy honrados,

$\mathrm{Y}$ a la mayor ${ }^{129}$ empresa apercividos:

Corren muy vastos Reynos sus blasones

Y hallan amigos, Reyes y Naciones.

En otra parte el Tlaxcalteca fuerte

Se opone a los triunfantes estrangeros:

No teme de la lid la dura suerte,

124 «tal vez», sin tachar.

125 «Mostrándose», tachado.

126 «alto», tachado.

127 « hizo ver», sin tachar.

128 Castilblanco es un pueblo de Badajoz, nombre que los españoles dieron al poblado que hoy es San Francisco de Ixtacamaxtitlan, que viene a significar lo mismo.

129 «mejor», tachado. 
Pero cede a su rayo y sus aceros.

Buela con su segur la impía Muerte;

Los más brabos perecen los primeros;

Los antípodas Héroes aturdidos

Huyen y se confiesan ya vencidos.

76

Xicontencali ${ }^{130}$, su caudillo osado,

Ofrece su amistad sumisamente;

Recívele CORTÉs muy moderado,

Y firma su alianza con tal Gente.

En otra parte el Yndio está emboscado,

Descúbrele Cortés astutamente,

Reprehende a los Gefes de Cholulla,

Y a muchos matan con motín y bulla.

77

Vese por otro lado Qualpopoca ${ }^{131}$,

Señor de Naucianzinco, muy osado,

Que con perfidia y vanidad ${ }^{132}$ muy loca

Nuestros Nuncios de Paz ha degollado;

Corre Hernán contra él, como le toca, Y el valor español queda vengado:

Los Yndios, admirando sus hazañas,

Esperan aún venturas más estrañas.

78

En lo sumo, CORTÉs su nombre llena

Y a su Dios y su Rey ${ }^{133}$ da gloria suma;

Entra en la grande México sin pena,

Y prende en su Palacio a Montezuma:

Más hechos de victoria tan amena

Dixera con placer mi pronta pluma,

Si apenas cesó el fuego, y quema clara

La aparición celeste no cesara.

130 Xicoténcatl es municipio de Tamaulipas, con el significado de «tierra de escarabajos».

131 Cacique ejecutado por Cortés.

132 «con sobervia», sin tachar.

133 «y a su Rei, y su Dios», sin tachar. 
El Patriotismo en tanto, muy gozoso,

Quiso cumplir de España los deseos,

Y estendiendo su brazo poderoso,

Transformó las pavesas en trofeos:

Del Parnaso al esmero primoroso

Le mandó efectuar estos empleos,

Y que lleve hasta el templo de la Gloria

De CORTÉs y sus Naves la memoria.

80

Él, apenas la escuadra consumida,

Vio estar la Cobardía desterrada,

Y cerradas las puertas a la huida,

Ordenó aparejarse a la jornada:

Dirigiose a la empresa concevida,

Con valor y prudencia concertada.

Y un triunfo consiguió tan no estrenado

Que exedió ${ }^{134}$ quanto havía imaginado.

Copiolas J. M. R. y C.

Año de 1779

A 22 de Dic.

En el original presentado al concurso figuran a continuación de la última octava la firma de catorce académicos, tras la frase latina de Trigueros: «Daret meliora Libertas».

134 «excedió», sin tachar. 